\title{
PENERAPAN SISTEM AKUNTANSI PENGGAJIAN DAN PENGUPAHAN PADA PT. INDOPERCUSSION DI GIANYAR
}

\author{
Ni Kadek Nopayanti ${ }^{1}$ \\ Luh Putu Virra Indah Perdanawati ${ }^{2}$ \\ Fakultas Ekonomi Universitas Ngurah Rai, Bali, Indonesia
}

\begin{abstract}
ABSTRAK
Penggajian dan pengupahan merupakan suatu alat yang dapat memotivasi karyawan untuk dapat melaksanakan tugas-tugasnya dengan baik dalam suatu perusahaan. Disamping itu penggajian dan pengupahan juga merupakan pengeluaran yang cukup besar bagi perusahaan. Agar penggajian dan pengupahan pada karyawan benar-benar mencerminkan keadilan dan bebas dari kecurangan-kecurangan, perlu disusun suatu sistem akuntansi yang memadai dalam perusahaan mengenai penggajian dan pengupahan. Untuk memperlancar jalannya operasional, PT. Indopercussion memerlukan penanganan penggajian dan penggupahan bagi karyawan bersangkutan. Metode pengumpulan data yang digunakan adalah dengan wawancara, dokumentasi. Untuk memecahkan permasalahan tersebut digunakan alat analisis kualitatif deskritif yaitu dengan cara membandingkan antara sistem akuntansi penggajian dan pengupahan sesuai dengan teori yang ada. Dari hasil tersebut dapat disimpulkan bahwa sistem akuntansi penggajian dan pengupahan pada PT. Indopercussion belum memadai, diantaranya surat pernyataan gaji dan upah tidak menguraikan dengan jelas tunjangan-tunjangan dan potongan-potongan yang diberikan kepada karyawan, adanya perangkapan tugas yang dapat mengakibatkan tugas-tugas yang dibebankan perusahaan bertumpuk pada satu bagian dan memungkinkan terjadi kecurangan yang dilakukan karyawan, unsur-unsur pengendalian intern yang terkait dalam sistem akuntansi penggajian dan pengupahan belum memadai karena fungsi pembuatan daftar gaji dan upah dan fungsi pembayaran gaji dan upah berada dalam satu bagian personalia, bagan alir dokumen sistem akuntansi penggajian dan pengupahan pada PT. Indopercussion belum memadai karena adanya perangkapan tugas.
\end{abstract}

Kata kunci : Sistem Akuntansi, Sistem Penggajian dan Pegupahan

\begin{abstract}
Payroll and remuneration is a tool that can motivate employees to be able to carry out their duties properly in a company. In addition, payroll and wages are also a considerable expense for the company. In order for payroll and remuneration of employees to truly reflect fairness and freedom from fraud, it is necessary to establish an adequate accounting system within the company regarding payroll and remuneration. To facilitate the operation, PT. Indopercussion requires the handling of remuneration and remuneration for the employee concerned. Data collection method used is by interview, documentation. To solve the problem used qualitative descriptive analysis tool that is by comparing between payroll accounting system and wages in accordance with existing theory. From these results can be concluded that the system of payroll accounting and wages at PT. Indopercussion is not sufficient, such as wage and salary statements do not clearly describe the allowances and deductions given to employees, the existence of task snatches that can result in the tasks assigned to the company piled on one section and allow for cheating by employees, The elements of internal control related in salary and payroll accounting system are not adequate because the function of making the payroll and wages and payroll and salary payment functions are in one part personnel, flow chart document payroll and payroll accounting system at PT. Indopercussion is inadequate due to multiple tasks.
\end{abstract}

Keywords: Accounting System, Payroll System and Wages multiple tasks. 


\section{PENDAHULUAN}

Tujuan utama berdirinya suatu perusahaan adalah untuk memperoleh laba yang maksimal dan dapat menjaga kelangsungan hidup perusahaannya. Sumber daya manusia dalam suatu perusahaan merupakan faktor dominan dalam pencapaian tujuan perusahaan. Sebagai imbalan kepada sumber daya tersebut, maka perusahaan memberikan serangkaian penghargaan di mana salah satu komponennya adalah gaji. Gaji mempunyai arti sebagai suatu penghargaan dari usaha karyawan atau tenaga kerja yang sudah pasti jumlahnya pada setiap waktu. Besarnya gaji atau upah idealnya merupakan hasil kesepakatan awal antara karyawan dan perusahaan sebagai ganti atas pengetahuan dan keterampilan yang diberikan karyawan kepada perusahaan. Perhitungan gaji atau upah dapat berdasarkan pada jam kerja, jumlah pekerjaan yang dapat diselesaikan, dan lain-lain. Pada pelaksanaannya, pemberian gaji atau upah harus dilakukan dengan professional agar hak dan kewajiban masing-masing pihak dapat terlaksana.

Kebutuhan ini akan terpenuhi dengan adanya sistem informasi akuntansi. Dalam memenuhi kebutuhan akan informasi yang baik dan benar guna pengambilan keputusan, bagi perusahaan maupun pihak luar yang membutuhkan, maka perlu disusun sistem akuntansi yang memadai dalam perusahaan. Sistem akuntansi adalah organisasi formulir, catatan dan laporan yang dikoordinasikan sedemikian rupa untuk menyediakan informasi keuangan yang dibutuhkan manajemen guna memudahkan pengelolaan perusahaan (Mulyadi, 2014:3). Suatu sistem dibentuk oleh jaringan-jaringan prosedur dan fungsi-fungsi yang terkait yang membentuk sistem akuntansi penggajian dan pengupahan yang memadai hendaknya mengandung unsur-unsur pengendalian intern, yang bertujuan untuk mencegah kemungkinan adanya kecurangan, serta adanya penggajian dan pengupahan yang melebihi jumlah sebenarnya. Sehingga dalam sistem akuntansi penggajian dan pengupahan terdapat pembagian-pembagian tugas yang dilakukan oleh bagian pencatat waktu, bagian pembuat daftar gaji dan upah serta bagian juru bayar gaji dan upah. Juga dalam sistem akuntansi penggajian dan pengupahan membuat perincian yang jelas kepada karyawan. Perincian yang jelas yang dibuat adalah perincian tentang besarnya gaji dan upah, serta tunjangan dan potongan yang harus diterima karyawan sesuai dengan ketetapan yang telah ditetapkan sebelumnya.

PT Indopercussion adalah Perusahaan Manufaktur, perusahaan yang memproses barang dari bahan mentah menjadi barang jadi/barang siap dipakai dan mengeksport. PT Indopercussion memproduksi barang dibidang Musical Instrument. PT Indopercussion memiliki 90 orang pegawai, yang dibagi menjadi tiga jenis pegawai yaitu pegawai tetap yang berjumlah 20 orang, Pegawai harian dan pegawai borongan yang berjumlah 70 orang. Sistem penggajian dan pengupahan hampir sama untuk staff dan harian akan dihitung menurut hari dan jam masuk kerja sedangkan pegawai borongan akan di hitung menurut berapa barang yang dapat mereka selesaikan per hari. Sistem pembagian gaji untuk pegawai tetap dan harian akan melalui rekening sedangkan borongan akan dibayar secara tunai yang akan di akumulasikan dalam sebulan. 
Adapun unsur-unsur yang belum memadai pada PT. Indopercussion adalah sebagai berikut :

a. Dokumen-dokumen yang digunakan dalam sistem akuntansi penggajian dan pengupahan pada PT. Indopercussion belum memadai, dapat dilihat dari surat pernyataan gaji dan upah tidak menguraikan dengan jelas mengenai tunjangan-tunjangan dan potonganpotongan yang diberikan kepada karyawan dan adanya perangkapan tugas yang dapat mengakibatkan tugas-tugas yang dibebankan perusahaan bertumpuk pada satu bagian dan memungkinkan terjadinya kecurangan yang dilakukan oleh karyawan.

b. Unsur-unsur pengendalian intern yang terkait dalam sistem akuntansi penggajian dan pengupahan belum memadai, karena fungsi pembuatan daftar gaji dan upah dan fungsi pembayaran gaji dan upah berada dalam satu bagian personalia.

c. Bagan alir sistem akuntansi penggajian dan pengupahan pada PT. Indopercussion belum memadai, karena adanya perangkapan tugas.

Pokok permasalahan penelitian ini berdasarkan latar belakang masalah yang dijelaskan, adalah : "Bagaimana pelaksanaan sistem akuntansi penggajian dan pengupahan pada PT. Indopercussion?',

\section{METODE PENELITIAN}

Penelitian ini dilakukan pada PT. Indopercussion yang berlokasi di Jalan Raya bay Pass Ida bagus Mantra, Medahan Gianyar. Yang menjadi obyek dalam penelitian ini adalah sistem akuntansi penggajian dan pengupahan. Sesuai dengan judul yang telah ditetapkan, maka identifikasi variabel yang akan digunakan dalam penelitiaan ini adalah sistem akuntansi penggajian dan pengupahan.

\section{HASIL DAN PEMBAHASAN}

Teknik analisis kualitatif deskriptif yang dipergunakan dalam penelitian ini yaitu suatu teknik analisis data dengan cara memaparkan dan membandingkan pelaksanaan sistem akuntansi penggajian dan pengupahan yang diterapkan PT. Indopercussion dengan 7 unsur sistem akuntansi penggajian dan pengupahan menurut Mulyadi.

a. Informasi yang diperlukan oleh manajemen pada PT.

Indopercussion di Gianyar dinilai sudah memadai karena sudah memberikan informasi secara terperinci kepada manajemen mengenai jumlah biaya gaji dan upah yang menjadi beban perusahaan selama periode tertentu dan jumlah gaji dan upah yang diterima oleh setiap karyawan selama periode akuntansi.

b. Dokumen yang digunakan dalam Sistem Akuntansi Penggajian dan pengupahan pada PT. Indopercussion di Gianyar :
1) Dokumen
Pendukung

Perubahan Gaji dan Upah

Dokumen pendukung perubahan gaji dan upah pada PT. Indopercussion di Gianyar dinilai sudah memadai karena dokumen ini informasi mengenai nama karyawan, nomor karyawan jabatan, dan rincian gaji dan upah yang terdiri dari gaji pokok, tunjangan jabatan, uang makan dan transport, premi asuransi kecelakaan kerja dan kematian, potongan-potongan berupa potongan Jamsostek, PPh Pasal 21, dan pinjaman karyawan dan 
mencantumkan ringkasan gaji per departemen.

2) Surat Pernyataan Gaji

Surat pernyataan gaji dan upah pada PT. Indopercussion di Gianyar dinilai sudah memadai karena dibuat oleh bagian personalia dan umum pada bulan berjalan. Dokumen ini mencatat nama karyawan, nomor karyawan, jabatan, dan rincian gaji yang terdiri dari gaji pokok, tunjangan jabatan, uang makan dan transport, potongan baik berupa potongan Jamsostek, PPh Pasal 21, dan pinjaman karyawan.

3) Amplop Gaji

Amplop gaji pada PT. Indopercussion di Gianyar diberikan kepada karyawan yang masih dalam masa kontrak. Pada bagian depan amplop gaji dan upah berisi informasi mengenai nama karyawan, nomor identifikasi karyawan dan jumlah gaji dan upah bersih yang diterima karyawan setiap awal bulan. Namun dinilai belum memadai karena pembagiannya dilakukan oleh bagian personalia dan umum bukan bagian keuangan (kasir).

4) Bukti Kas Keluar

Bukti kas keluar pada PT. Indopercussion di Gianyar dinilai belum memadai karena bukti kas keluar dibuat rangkap 2 sehingga bagian personalia dan umum tidak memperoleh arsip. Bukti kas keluar dibuat oleh bagian keuangan (kasir) berdasarkan rekap daftar gaji dan upah yang diberikan oleh bagian personalia dan umum. c. Catatan akuntansi yang digunakan dalam sistem akuntansi penggajian dan pengupahan pada PT. Indopercussion di Gianyar adalah :

1) Jurnal Umum

Jurnal umum pada PT. Indopercussion di Gianyar sudah memadai karena dibuat oleh fungsi akuntansi untuk mencatat pengeluaran akan biaya gaji dan upah per bulan.

2) Kartu Penghasilan Karyawan

Kartu penghasilan karyawan pada PT. Indopercussion di Gianyar dinilai sudah memadai karena digunakan sebagai tanda terima gaji dan upah dan ditandatangani oleh karyawan itu sendiri.

d. Fungsi-fungsi yang terkait dalam sistem akuntansi penggajian dan pengupahan pada PT. Indopercussion di Gianyar dinilai belum memadai karena masih adanya perangkapan tugas yang dilakukan oleh bagian personalia dan umum seperti menguangkan cek ke bank dan memberikan gaji dan upah secara tunai yang sudah disiapkan dalam amplop gaji dan upah kepada karyawan yang masih dalam masa kontrak. Dimana tugas tersebut seharusnya dilakukan oleh bagian keuangan (kasir).

e. Jaringan prosedur yang membentuk Sistem Akuntansi Penggajian dan Pengupahan pada PT. Indopercussion di Gianyar adalah :

1) Prosedur Pencatatan Waktu Hadir

Prosedur pencatatan waktu hadir pada PT. Indopercussion di Gianyar dinilai belum memadai karena pencatatan waktu hadir karyawan dengan mesin check lock tanpa pengawasan. 
2) Prosedur Pembuatan Daftar Gaji dan Upah

Prosedur pembuatan daftar gaji dan upah pada PT. Indopercussion di Gianyar dinilai sudah memadai karena dibuat oleh bagian personalia dan umum berdasarkan daftar hadir karyawan dan dokumen pendukung perubahan gaji dan upah apabila ada perubahan gaji dan upah pada bulan berlaku.

3) Prosedur Pembuatan Bukti Kas Keluar

Prosedur pembuatan bukti kas keluar pada PT. Indopercussion di Gianyar dinilai sudah memadai karena dilakukan oleh bagian kasir berdasarkan rekap daftar gaji yang diberikan oleh bagian personalia dan umum.

4) Prosedur pembayaran Gaji dan upah

Prosedur pembayaran gaji dan upah pada PT. Indopercussion di Gianyar dinilai belum memadai karena fungsi akuntansi yang menulis cek dimana seharusnya dilakukan oleh fungsi keuangan (kasir), fungsi kepegawaian (personalia dan umum) yang menguangkan cek ke bank dan melakukan pembayaran gaji dan upah kepada karyawan yang masih dalam masa kontrak dimana uang gaji dan upah dimasukkan ke dalam amplop gaji dan upah yang sudah disiapkan oleh fungsi kepegawaian (personalia dan umum) dimana tugas tersebut seharusnya dilakukan oleh fungsi keuangan (kasir).

f. Unsur Pengendalian Intern dalam Sistem Akuntansi Penggajian dan
Pengupahan pada PT. Indopercussion di Gianyar adalah :

1) Organisasi pada PT. Indopercussion di Gianyar belum memadai karena fungsi pembuatan daftar gaji dan upah dan fungsi pembayaran gaji dan upah masih dikerjakan oleh bagian personalia dan umum.

2) Sistem otorisasi pada PT. Indopercussion di Gianyar dinilai sudah memadai karena :

(1) Setiap orang yang namanya tercantum dalam daftar gaji dan upah memiliki surat keputusan pengangkatan sebagai karyawan perusahaan yang ditandatangani oleh direktur utama.

(2) Perubahan pada gaji dan upah karyawan karena perubahan pangkat, perubahan tarif gaji dan upah, tambahan keluarga didasarkan pada surat keputusan direktur.

(3) Potongan atas gaji dan upah karyawan selain dari pajak penghasilan karyawan berdasarkan surat potongan gaji dam upah yang diotorisasi oleh fungsi kepegawaian atau bagian personalia dan umum.

(4) Daftar hadir diotorisasi oleh bagian personalia dan umum

(5) Daftar gaji dan upah diotorisasi oleh bagian personalia dan umum

(6) Bukti kas keluar diotorisasi oleh bagian kasir

3) Praktek yang sehat pada PT. Indopercussion di Gianyar :

(1) Pencatatan waktu hadir dinilai belum memadai 


\section{karena belum ada pengawasan dalam pencatatan waktu hadir karyawan. \\ (2) Perhitungan penghasilan karyawan dinilai sudah memadai karena setahun direkonsiliasi dengan daftar gaji dam upah dan kartu penghasilan karyawan.}

g. Bagan Alir Dokumen pada PT. Indopercussion di Gianyar Bagan alir dokumen sistem akuntansi penggajian dan pengupahan pada PT. Indopercussion di Gianyar dinilai belum memadai.

\section{Simpulan}

Berdasarkan deskripsi dan analisis terhadap tujuh unsur sistem akuntansi penggajian dan pengupahan pada PT. Indopercussion di Gianyar yang diterapkan pada PT. Indopercussion di Gianyar perlu disempurnakan lagi karena ada beberapa temuan sebagai berikut :

a. Informasi yang diperlukan oleh manajemen pada PT. Indopercussion di Gianyar dinilai sudah memadai.

b. Dokumen yang digunakan dalam sistem akuntansi penggajian dam pengupahan pada PT. Indopercussion di Gianyar yaitu dokumen pendukung perubahan gaji dan upah, kartu jam hadir, rekap daftar gaji dan upah, surat pernyataan gaji dan upah dinilai sudah memadai. Daftar gaji dan upah dan bukti kas keluar dinilai belum memadai. Amplop gaji dan upah dinilai belum memadai.

c. Catatan akuntansi yang digunakan dalam sistem akuntansi penggajian dan pengupahan pada PT. Indopercussion di Gianyar di yaitu jurnal umum dan kartu penghasilan karyawan dinilai sudah memadai.

d. Fungsi-fungsi yang terkait dalam sistem akuntansi penggajian dam pengupahan pada PT. Indopercussion di Gianyar dinilai belum memadai.

e. Jaringan prosedur yang membentuk sistem akuntansi penggajian dan pengupahan pada PT. Indopercussion di Gianyar yaitu prosedur pembuatan daftar gaji dan upah prosedur pembuatan bukti kas keluar dinilai sudah memadai. Prosedur pencatatan waktu hadir dinilai belum memadai. Prosedur pembayaran gaji dan upah pada PT. Indopercussion di Gianyar dinilai belum memadai.

f. Unsur pengendalian intern dalam sistem akuntansi penggajian dan pengupahan pada PT. Indopercussion di Gianyar yaitu organisasi dinilai belum memadai. Sistem otorisasi dinilai sudah memadai. Praktek yang sehat terhadap pencatatan waktu hadir dinilai belum memadai. Sedangkan praktek yang sehat terhadap perhitungan pajak penghasilan karyawan dinilai sudah memadai.

g. Bagan alir dokumen pada PT. Indopercussion di Gianyar dinilai belum memadai.

\section{Saran}

Berdasarkan kesimpulan diatas maka saran-saran yang dapat dikemukakan sebagai pertimbangan dalam melakukan perbaikan terhadap sistem akuntansi penggajian dan pengupahan pada PT. Indopercussion di Gianyar yaitu : 
a. Pada dokumen yang digunakan seperti daftar gaji dan upah dan bukti kas keluar ditambahkan rangkapnya sehingga dapat diarsip guna menghindari kelalaian yang dilakukan oleh karyawan. Sedangkan amplop gaji dan upah sebaiknya pembagiannya dilakukan oleh bagian kasir.

b. Fungsi-fungsi yang terkait dimana yang menguangkan cek ke bank serta pembayaran gaji dan upah kepada karyawan sebaiknya dilakukan oleh bagian kasir.

c. Pencatatan waktu hadir karyawan hendaknya dilakukan pengawasan sehingga terhindar dari penyelewengan jam kerja atau kekurangan dalam perhitungan biaya gaji dan upah karyawan. Pada prosedur pembayaran gaji dan upah sebaiknya dilakukan oleh bagian kasir.

d. Organisasi dalam unsur pengendalian intern sebaiknya dikerjakan oleh fungsi yang terpisah agar terhindar dari kesalahan-kesalahan dalam perhitungan biaya gaji dan upah. Perlu adanya pengawasan dalam pencatatan waktu hadir agar tidak terjadi kecurangan-kecurangan dalam perhitungan gaji dan upah karyawan.

e. Bagan alir pada PT. Indopercussion di Gianyar, perlu disempurnakan.

\section{REFERENSI}

Adikusumah, Soemita R., (2009), Anggaran Perusahaan 2, Edisi 1, BPFE, Yogyakarta.

Agus Sugiarta, (2013), Evaluasi Sistem Akuntansi Pembayaran Gaji pada CV. Cahaya Bali,, Skripsi,
Jurusan Akuntansi, Universitas Warmadewa Denpasar.

Arikunto, Suharsimi, (2009), Prosedur Penelitian Suatu Pendekatan Praktis, Penerbit Rineka Cipta, Jakarta.

Cole dan Neuschel, (2009), Sistem Informasi Akuntansi. Edisi Keenam. Jakarta : Salemba Empat.

Daryanto, H., (2009), Evaluasi Pendidikan Dasar, Jakarta : PT. Bumi Aksara.

Dewi Purwanti Suwarno, (2014), Evaluasi Sistem Akuntansi Penggajian Pada PT. Sinar Kumala Indah di Denpasar, Skripsi, Jurusan Akuntansi, Universitas Warmadewa Denpasar.

Fakultas Ekonomi, (2016), Buku Pedoman Penyusunan Skripsi, Universitas Ngurah Rai.

Hall, James, (2009), Sistem Akuntansi dan Informasi, Edisi Kedua, Jakarta : Erlangga.

Hendri Yudhi Novianto, (2013), Evaluasi Sistem Akuntansi Penggajian dan Pengupahan pada PT. Karunia Abadi Finance di Denpasar, Skripsi, Jurusan Akuntansi, Universitas Warmadewa Denpasar.

Husaini Usman dan R. Purnomo Setiady Akbar, (2009), Pengantar Statistika, Edisi Kedua, Bumi Aksara, Jakarta.

Mulyadi, (2014), Sistem Akuntansi, Edisi 3, Jakarta : Salemba Empat.

Nur Indriantoro dan Bambang Supomo, (2009), Metodelogi Penelitian Bisnis, Untuk Akuntansi dan Manajemen, Penerbit BPFE, Yogyakarta.

S.R., Soemarno (2009), Metodelogi Penelitian Bisnis, Untuk 
Akuntansi dan Manajemen, BPFE Universitas Diponegoro, Yogyakarta.

Sugiyono, (2014), Statistika Untuk Penelitian, Cetakan ke-21, Penerbit CV. Alfabeta, Bandung.

Wilkinson, Joseph W, (2009), Sistem Akuntansi dan Informasi, Edisi Kedua, Cetakan Pertama, Jakarta : Erlangga. 